\title{
Proteção a Murcha de Fusário do Tomateiro com Acibenzolar-S- Metil e Ácido $\beta$-Aminobutírico, em Campo
}

\author{
Luciana M. S. Gurgel, Sônia M. A. de Oliveira, Rildo S. B. Coêlho \& Roberto L. X. da Silva \\ UFRPE, Depto. de Agronomia, Área de Fitossanidade, Rua Dom Manoel de Medeiros, S/N, \\ Dois Irmãos, CEP 52171-900, Recife, PE
}

(Aceito para publicação em 20/10/2005)

Autor para correspondência: Luciana M. S. Gurgel

GURGEL, L.M.S., OLIVEIRA, S.M.A., COÊLHO, R.S.B. \& SILVA, R.L.X. Proteção à murcha de fusário do tomateiro com acibenzolar-S-metil e ácido â-aminobutírico. Fitopatologia Brasileira 30:655-657. 2005.

\section{RESUMO}

Os elicitores abióticos são compostos que induzem a síntese de fitoalexinas, como também outras respostas de defesa da planta. Visando a obtenção de uma alternativa de controle para murcha de fusário do tomateiro (Lycopersicon esculentum) foram avaliados os indutores Acibenzolar-S-Metil (ASM) e Ácido $\beta$-Aminobutírico (BABA), em diferentes doses e épocas de aplicação via foliar. Foram utilizadas as cultivares Viradoro e IPA-6, suscetíveis a raça 1 de Fusarium oxysporum f.sp. lycopersici. A avaliação de sintomas externos foi realizada semanalmente e a avaliação final realizada aos 43 dias após a inoculação das plantas, através da análise de sintomas externo e interno, utilizando-se duas escalas de notas. Apenas na cv. IPA-6 houve redução no índice de doença no tratamento com BABA na maior dose, aplicado cinco dias antes da inoculação.

Palavras-chave adicionais: Lycopersicon esculentum, indutores de resistência, Fusarium oxysporum f.sp. lycopersici.

\begin{abstract}
Protection of tomato Fusarium wilt with acibenzolar-S-methyl and $\beta$-aminobutiric acid in field

With the objective of finding an alternative control of Fusarium wilt on tomato (Lycopersicon esculentum), Acibenzolar-S-Methyl (ASM) and $\beta$-Aminobutiric acid (BABA) inductors were sprayed on leaves using different doses and application periods. Two tomato cultivars, Viradoro and IPA-6 were used in the study. An evaluation of external symptoms was done weekly and the final evaluation was carried out until 43 days after inoculation by looking at both the inside and outside of the stem, using two note scales. For IPA-6, the best treatment was with BABA, five days before inoculation.
\end{abstract}

Additional keywords: Lycopersicon esculentum, induction of resistance, Fusarium oxysporum f.sp. lycopersici.

A cultura do tomateiro (Lycopersicon esculentum Mill.) é afetada por diversas doenças de importância econômica, destacando-se a murcha de fusário causada por Fusarium oxysporum Schlecht f.sp. lycopersici Snyder \& Hansen (FOL), cujo controle fundamenta-se no uso de cultivares resistentes (Kurozawa \& Pavan, 1997). Em face de indisponibilidade de cultivares com resistência e, em alguns casos, a necessidade do uso de cultivares suscetíveis mais produtivas, métodos de controle alternativos devem ser pesquisados neste patossistema. Nesse contexto, a resistência sistêmica adquirida (RSA) pode ser uma alternativa viável no controle da murcha de fusário. A RSA resulta da ativação do sistema de defesa da planta, por elicitores bióticos e abióticos, com a expressão de mecanismos relacionados com a produção de substâncias tóxicas ao patógeno e/ou formação de barreiras estruturais que restringem a colonização dos tecidos (Kuc, 2001). A RSA é ativada de forma sistêmica na planta, contra amplo espectro de patógenos, sendo o ácido salicílico (AS) uma das moléculas sinais na síntese de compostos de defesa (Durrant \& Dong, 2004). Vários trabalhos mostraram a eficiência do acibenzolar-S- metil (ASM) e ácido â-aminobutírico (BABA) induzindo proteção contra diferentes patógenos através da ativação da RSA (Cohen et al., 1999; Jeun \& Buchenauer, 2001). Este trabalho teve como objetivo testar os indutores químicos ASM e BABA, em diferentes doses e épocas de aplicação, na indução de resistência do tomateiro a murcha de fusário.

Plantas de tomateiro das cvs. Viradoro e IPA-6 foram cultivadas em bandejas e aos 24 dias após a semeadura, as mesmas foram transplantadas. Os indutores ASM e BABA foram aplicados via foliar cinco e dez dias, em tratamentos independentes, antes da inoculação com o patógeno, utilizando duas doses: ASM 25 e $50 \mathrm{mg} / \mathrm{l}$ de água e BABA 15 e $30 \mathrm{mg} / \mathrm{l}$ de água. A concentração de conídios foi ajustada para $10^{6}$ conídios $/ \mathrm{ml}$. A inoculação foi realizada 50 dias após a semeadura, através do ferimento de raízes em meia lua aplicando-se $50 \mathrm{ml}$ da suspensão/planta. A avaliação de sintomas externos foi realizada semanalmente com escala de notas (Nielsen \& Haynes, 1960). A avaliação final foi realizada aos 43 dias após a inoculação avaliando-se sintomas externo e interno, com as escalas de notas de Nielsen \& Haynes (1960), e a de Tokeshi \& Galli (1976) 
avaliando os sintomas internos. Com os dados obtidos foi calculado o índice de Mckinney. O delineamento estatístico foi o de blocos ao acaso, com quatro repetições/tratamento. A severidade da doença foi submetida à análise de variância e as médias comparadas pelo teste de Tukey $(\mathrm{P}=0.05)$, utilizando o programa SANEST.

$\mathrm{Na}$ avaliação dos sintomas externos verificou-se que redução significativa no índice de doença somente ocorreu com aplicação de BABA na cv. IPA-6 na maior dose, aplicado cinco dias antes da inoculação. Resultados similares foram obtidos na avaliação dos sintomas internos (Tabela 1). Gurgel (2004) estudando o comportamento de cultivares de tomateiro induzidas com BABA, ASM, quitosana e jasmonato, verificou uma melhor proteção contra FOL em IPA-6 e Viradoro, com BABA. Através dos sintomas externos, observa-se de modo geral, que as plantas responderam a aplicação dos indutores, com menores níveis de severidade em todos os tratamentos, em relação à testemunha, onde BABA foi mais eficiente que ASM (Figura 1) por um período de 21 dias. Resultados contrários foram obtidos por Rodrigues et al. (2003), onde BABA foi menos efetivo no controle da murcha de fusário em caupi. Já Cohen et al. (1994), verificaram que BABA aplicado em plantas de tomateiro contra Phytophthora infestans (Mont.) De Bary proporcionou proteção por 12 dias. De acordo com Cohen (2002), a duração da resistência induzida por BABA depende do patossistema e do modo de aplicação do indutor. $\mathrm{Na}$ cv. Viradoro, o progresso da doença foi mais lento do que na testemunha, quando ASM e BABA foram aplicados cinco e dez dias antes da inoculação. Plantas suscetíveis de tomateiro desenvolveram resistência sistêmica ao $F$. oxysporum f.sp. radicis-lycopersici em resposta a aplicação de ASM, diminuindo significativamente o número de lesões nas raízes e reduzindo o desenvolvimento da doença através da formação de barreiras

TABELA 1 - Índice de Mckinney em função de doses e épocas de aplicação foliar dos indutores ácido â-aminobutírico (BABA) e acibenzolar-S-metil (ASM), sob condições de campo em tomateiro (Lycopersicon esculentum) contra murchade-fusário ocasionada por Fusarium oxysporum f.sp. lycopersici

\begin{tabular}{|c|c|c|c|c|c|c|}
\hline \multirow{3}{*}{ Indutor } & \multirow{3}{*}{ Cultivar } & \multirow{3}{*}{$\begin{array}{c}\text { Dose } \\
\left(\mathrm{mgl}^{-1}\right)\end{array}$} & \multirow{2}{*}{\multicolumn{2}{|c|}{$\begin{array}{c}\text { Sintomas Externos } \\
\text { Época de Aplicacação (dias) }\end{array}$}} & \multirow{2}{*}{\multicolumn{2}{|c|}{$\begin{array}{c}\text { Sintomas Internos } \\
\text { Época de Aplicação (dias) }\end{array}$}} \\
\hline & & & & & & \\
\hline & & & 5 & 10 & 5 & 10 \\
\hline \multirow[t]{6}{*}{ BABA } & IPA -6 & 0 & $91.6 \mathrm{aA}^{*}$ & $91.6 \mathrm{aA}^{*}$ & $93.7 \mathrm{aA}^{*}$ & $93.7 \mathrm{aA}^{*}$ \\
\hline & & 15 & $81.2 \mathrm{abA}$ & $93.7 \mathrm{aA}$ & $85.8 \mathrm{abA}$ & $94.9 \mathrm{aA}$ \\
\hline & & 30 & $46.3 \mathrm{bB}$ & $80.7 \mathrm{aA}$ & $59.1 \mathrm{bA}$ & $81.2 \mathrm{aA}$ \\
\hline & Viradoro & 0 & $88.5 \mathrm{aA}$ & $88.5 \mathrm{aA}$ & $77.1 \mathrm{aA}$ & $77.1 \mathrm{aA}$ \\
\hline & & 15 & 70.8 a A & $61.4 \mathrm{aA}$ & $65.4 \mathrm{aA}$ & $65.4 \mathrm{aA}$ \\
\hline & & 30 & $70.3 \mathrm{aA}$ & $68.7 \mathrm{aA}$ & $71.2 \mathrm{aA}$ & $56.2 \mathrm{aA}$ \\
\hline \multirow[t]{6}{*}{ ASM } & IPA -6 & 0 & $91.6 \mathrm{aA}^{*}$ & $91.6 \mathrm{aA}$ & $93.7 \mathrm{aA}$ & $93.7 \mathrm{abA}$ \\
\hline & & 25 & $90.1 \mathrm{aA}$ & $100.0 \mathrm{aA}$ & $95.0 \mathrm{aA}$ & $100.0 \mathrm{aA}$ \\
\hline & & 50 & $79.7 \mathrm{aA}$ & $75.0 \mathrm{aA}$ & $85.0 \mathrm{aA}$ & $68.75 \mathrm{bA}$ \\
\hline & Viradoro & 0 & $88.5 \mathrm{aA}$ & $88.5 \mathrm{aA}$ & $77.1 \mathrm{aA}$ & $77.1 \mathrm{aA}$ \\
\hline & & 25 & $68.7 \mathrm{aA}$ & $90.1 \mathrm{aA}$ & $76.6 \mathrm{aA}$ & $85.0 \mathrm{aA}$ \\
\hline & & 50 & $100.0 \mathrm{aA}$ & $87.5 \mathrm{aA}$ & $97.1 \mathrm{aA}$ & $90.0 \mathrm{aA}$ \\
\hline
\end{tabular}

*Médias seguidas pela mesma letra minúscula, na vertical e maiúscula na horizontal, não diferem entre si estatisticamente, pelo teste de Tukey ao nível de $5 \%$ de probabilidade. Médias de quatro repetições por tratamento.
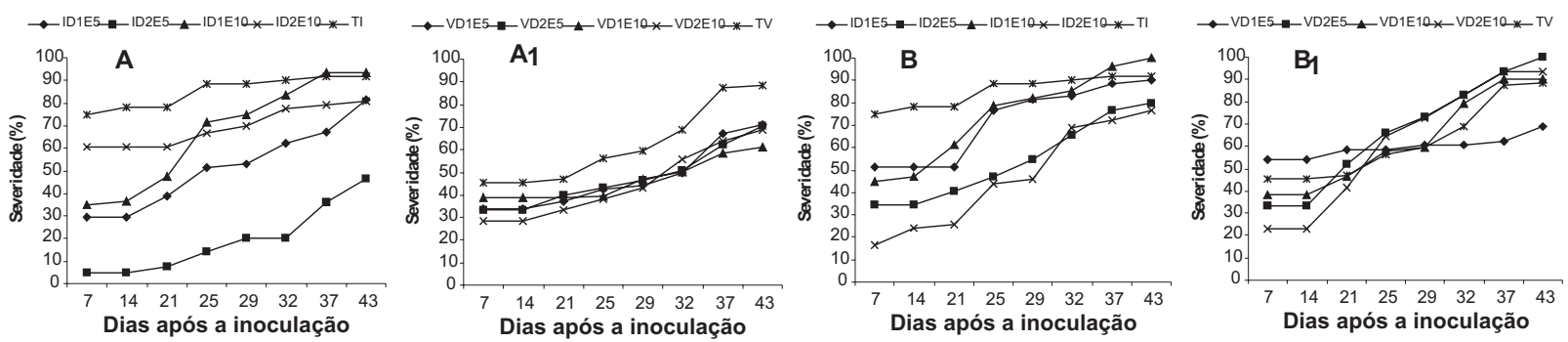

FIG 1 - Progresso da murcha de fusário em cultivares de tomateiro (Lycopersicon esculentum), IPA-6 (I) e Viradoro (V), em resposta a indução com ácido â-aminobutírico (BABA) (A e $A_{1}$ ) e Acibenzolar-S-Metil (ASM) (B e $B_{1}$ ), utilizando duas dosagens e épocas de aplicação. D1: $15 \mathrm{mg} \cdot 1^{-1}$ (BABA), $25 \mathrm{mg} \cdot 1^{-1}$ (ASM), D2: $30 \mathrm{mg} \cdot \mathrm{l}^{-1}$ (BABA), $50 \mathrm{mg} \cdot \mathrm{l}^{-1}$ (ASM), E5: aplicação do indutor cinco dias antes da inoculação; E10: aplicação do indutor dez dias antes da inoculação; T=testemunha. 
estruturais (Benhamou \& Bélanger, 1998). A proteção expressiva nas primeiras avaliações sugere que inicialmente as plantas responderam mais rapidamente ao patógeno, quando elicitadas com ASM e BABA, do que a testemunha, que foi induzida apenas pelo fungo. Dixon \& Lamb (1990) afirmaram que o sucesso da colonização do patógeno em plantas suscetível e resistente é devido ao atraso da expressão da RSA, e não pela ausência da mesma. Segundo Benhamou et al. (1994), a rapidez com que a planta responde ao patógeno determina a eficiência da resistência de um hospedeiro considerado suscetível. O BABA constitui uma alternativa de controle para a murcha de fusário no tomateiro.

\section{REFERÊNCIAS BIBLIOGRÁFICAS}

BENHAMOU, N. \& BËLANGER, R.R. Benzothiadiazolemediated induced resistance to Fusarium oxysporum f.sp. radicislycopersici in tomato. Plant Physiology 118:1203-1212. 1998.

BENHAMOU, N., LAFONTAINE, P.J. \& NICOLE, N. Induction of systemic resistance to Fusarium crown and root rot in tomato plants by seed treatment with chitosan. Phytopathology $84: 1432-$ 1444. 1994.

COHEN, Y. â- Aminobutyric acid-induced resistance against plant pathogens. Plant Disease 86:448-457. 2002.

COHEN, Y., NIDERMAN, T., MOSINGER, E. \& FLUHR, R. âaminobutyric acid induces the accumulation of pathogenesisrelated proteins in tomato (Lycopersicon esculentum Mill.) plants and resistance to late blight infection caused by Phytophthora infestans. Plant Physiology 104:59-66. 1994.

COHEN, Y., REUVENI, M. \& BAIDER, A. Local and systemic activity of BABA (DL-3-aminobutyric acid) against Plasmopara viticola in grapevines. European Journal of Plant Pathology 105:351-361. 1999

DIXON, R.A. \& LAMB, C.J. Molecular communication in interactions between plants and microbial pathogens. Annual
Review of Plant Physiology and Molecular Biology 41:339-367. 1990.

DURRANT, W.E. \& DONG, X. Systemic acquired resistance. Annual Review of Phytopathology 42:185-209. 2004.

GURGEL, L.M.S. Resistência sistêmica induzida em cultivares de tomateiro à murcha de fusário: indutores químicos, mecanismos de defesa envolvidos e eficiência de controle no campo. (Tese de Doutorado). Recife. Universidade Federal Rural de Pernambuco. 2004.

JEUN, Y.C. \& BUCHENAUER, H. Infection structures and localization of the pathogenesis-related protein AP24 in leaves of tomato plants exhibiting systemic acquired resistance against Phytophthora infestans after pre-treatment with 3-aminobutyric acid or tobacco necrosis virus. Journal of Phytopathology 149:141153. 2001.

KUC, J. Concepts and direction of induced systemic resistance in plants and its application. European Journal of Plant Pathology 107:7-12. 2001

KUROZAWA, C. \& PAVAN, M.A. Doenças do Tomateiro (Lycopersicon esculentum Mill). In: Kimati, H., Amorim, L., Bergamin Filho, A., Camargo, L.E.A. \& Rezende, J.A.M. (Eds.) Manual de Fitopatologia: Doenças de plantas cultivadas, 3.ed., São Paulo: Agronômica Ceres, 1997, v.2, p.690-719.

NIELSEN, L.W. \& HAYNES, F.L. Resistance in Solanum tuberosum to Pseudomonas solanacearum. American Potato Journal 37:260-267. 1960

RODRIGUES, A.A.C. Resistência de caupi a Fusarium oxysporum f.sp. tracheiphilum: Avaliação de germoplasmas, indução de defesa, caracterização de mecanismos bioquímicos, estruturais e análise da capacidade funcional do xilema. (Tese de Doutorado). Recife. Universidade Federal Rural de Pernambuco. 2003.

STICHER, L., MANI, B.M. \& MÉTRAUX, J.P. Systemic acquired resistance. Annual Review Phytopathology 35:235-270. 1997.

TOKESHI, H. \& GALLI, F. Variabilidade de Fusarium oxysporum f. sp. lycopersici (wr.) Sny \& Hans em São Paulo. Anais da Escola Superior de Agricultura Luiz de Queiroz 23:195-209. 1966. 